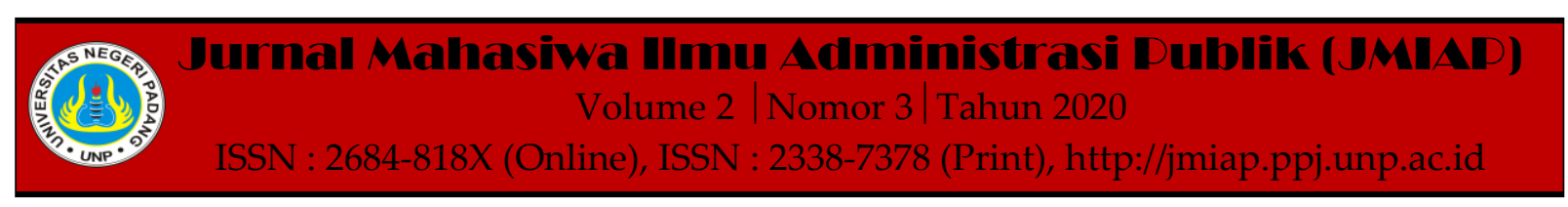

\title{
PENGARUH BUDAYA KERJA TERHADAP KESELAMATAN KESEHATAN KERJA DINAS PEMADAM KEBAKARAN KOTA PADANG
}

\author{
Afrinia Winriyani ${ }^{1(a)}$ Aldri Frinaldi ${ }^{2(b)}$ \\ ${ }^{1}$ Jurusan Ilmu Administrasi Negara, Universitas Negeri Padang \\ ${ }^{2}$ Jurusan Ilmu Administrasi Negara, Universitas Negeri Padang \\ a)afriniawinriyani@gmail.com, ${ }^{b)}$ aldri@fis.unp.ac.id
}

\begin{abstract}
This research is based on the problems of work culture and occupational health safety of the padang city fire service. The purpose of this study is to analyze how much the influence of work culture on occupational health safety of padang fire service. This research used quantitative method, with descriptive technique. The technique sampling was done by purposive sampling. Quantitative data is collected using Likert Scale numbers that have been tested for validity and reability. The population of the sample is 120 employees. In this study, it can be seen that there is a positive effect of work culture on occupational health safety of the padang city fire service that has been tested with a value, and obtained a small significance value of 0.000 out of 0.05 and the percentage contribution of variable $X$ to $Y$ of $37.1 \%$. The value listed in this study is that the better the work culture, the better it can shape the safety of occupational health. This research was conducted to improve the cultural aspects of work in improving the occupational health safety of the padang city fire service.
\end{abstract}

Keywords : Work Culture, Safety, Occupational Health

Corresponding author.Email.afriniawinriyani@gmail.com,aldri@fis.unp.ac.id

How to cite this article. Winriyani, A \& Frinaldi, A. (2020). Pengaruh Budaya Kerja terhadap Keselamatan Kesehatan Kerja Dinas Pemadam Kebakaran Kota Padang. Jurnal Mahasiwa Ilmu Administrasi Publik (JMIAP) Jurusan Ilmu Administrasi Negara Fakultas Ilmu Sosial Universitas Negeri Padang, Volume 2 (3), Hal. 34-40.

http://jmiap.ppj.unp.ac.id

ISSN : 2684-818X (Online), ISSN : 2338-7378 (Print)

Copyright $\odot 2020$. Published by Labor Jurusan Ilmu Administrasi Negara FIS UNP, Padang 


\section{PENDAHULUAN}

Dalam menghadapi perkembangan era globalisasi pemerintah saat ini di tuntut untuk bisa meningkatkan kinerja pegawai. Adapun aspek terpenting yang sangat perlu ditingkatkan ialah sumber daya manusia dengan meningkatkan skill yang dimiliki nya seperti keterampilan pada saat melaksanakan pekerjaanya. Sehingga dengan meningkatnya skill yang dimiliki pegawai maka secara tidak langsung bisa meningkatkan kinerja pegawai tersebut.

Ada beberapa factor pengaruh kinerja pegawai di instansi pemerintah salah satunya ialah budaya kerja. Budaya kerja yang dimaksud ialah budaya kerja yang baik. Karena budaya kerja akan mempengaruhi sikap pegawai dalam bekerja, termasuk bagaimana cara Pemimpin dalam mengelola pegawainya (Aldri, 2014).

Pada sebuah intansi akan terjalankan sebuah budaya kerja positif yang kuat dalam bekerja jika terdapat sinegisitas sejalan antara pegawai dan pimpinannya. Namun masih ada penerapan budaya kerja positif yang belum merata sehingga menimbulkan asumsi seperti mana terdapat pegawai yang tidak memiliki budaya kerja yang positif. (Aldri, 2014).

Triguno dalam Aldri Frinaldi (2011:53) Budaya kerja merupakan filsafat didasarkan pada pandangan hidup seperti kebiasaan, nilai-nilai menjadi sifat dan pendorong membudaya di dalam kehidupan kelompok masyarakat dan organisasi akan tergambarkan melalui keyakinan cita-cita dan kelakuan sehingga terwujud kerja maupun bekerja.

Pada penelitian ini aspek yang sangat ditonjolkan adalah budaya kerja. Budaya kerja merupakan dasar alamiah seseorang yang bisa dilihat secara langsung maupun tidak langsung yang berbentuk tingkahlaku maupun komunikasi.

Budaya kerja merupakan salah satu aspek terpenting dalam upaya peningkatan budaya kerja dinas pemadam kebakaran kota padang adalah keselamatan kesehatan kerja, karena dilingkungan kerja kondisi kinerja pegawai di dinas pemadam kebakaran kota padang sangat memiliki beberapa tantangan dalam bahaya terkait menangani kebakaran, api dan sebagainya. Untuk itu perlu penting untuk pegawai bisa menanamkan keselamatan kesehatan kerja baik itu dari itu prosedural, fasilitas dan sebagainya.

Merujuk Undang-Undang Nomor 1 Tahun 1970 tentang keselamatan kerja tentadengan adanya peraturan perundangan telah ditetapkan tentang persyaratan keselamatan kerja yaitu mencegah kebakaran, mengurangi bahaya peledakan kemudian dan terselamatankan diri pada saat kebakaran.

Bencana yang sering terjadi di Indonesia yaitu kebakaran, disebabkan oleh: korlesting, pemasakan, kebocoran gas elpiji. Berbagai factor antara lain: 1) Terjadinya kebakaran yang disebabkan oleh kelalaian manusia, 2) Kekurangan tata cara teknis tidak sesuai dengan prinsp keselamatan kerja , 3) seperti letusan gunung berapi, gempa bumi, petir.

Melalui kajian dilapangan pada tanggal 21 Januari 2020, jelas bahwa budaya kerja dan keselamatan kesehatan kerja ada beberapa masalah seperti kurangnya keselamatan kesehatan kerja yang ada di Dinas Pemadam Kebakar. Hal ini sesuai dengan wawancara bersama bapak $S$ seorang Petugas Damkar :

“...Seperti yang bapak $S$ jelaskan sebagai petugas Dinas Pemadam Kebakaran Kota Padang bahwa petugas pemadam kebakaran masih terdapat pegawai yang kurang bersosialisasi antara pegawai. Disini juga sering terjadi kecelakaan kerja karena pekerjaan mereka merupakan salah satu pekerjaan yang memiliki resiko kecelakaan yang sangat tinggi karena berhubungan langsung dengan situasi yang dapat membahayakan diri untuk menyelamatkan orang lain.

Hasil wawancara tergambar diatas masih adanya persoalan yaitu: masih kurangnya komunikasi antara sesama pegawai sehingga kurangnya pembinaan 
atasan kepada bawahan. Selanjutnya masih adanya petugas yang tidak mematuhi peraturan terutama dalam penampilan, masih terjadinya kecelakaan kerja saat melaksanakan pekerjaan.

Untuk memperjelas mengenai persoalan budaya kerja dan keselamatan kesehatan kerja dinas pemadam kebakaarn kota padang, maka penulis mealakukan wawancara pada tanggal 28 januari 2020. Hal ini sesaui dengan wawancara bpk $\mathrm{H}$ seorang petugas pemadam kebakaran kota padang.

"...Masih terdapat sebagian petugas yang kurang besosialisasi antara sesame petugas karena pada dasarnya petugas ini bekerja langsung turun kelapangan, akibatnya akan menimbulkan kurangnya komunikasi antara personal. Kemudian petugas pemadam kebakaran saat melaksanakan pekerjaannya mengalami kecelakaan saat bekerja diakibatkan lalainya para pekerja dalam melakukan pekerjaannya. Seperti terjatuh dari mobil saat melaksanakan tugas tetapi hanya cedera biasa, jatuh darin gedung atau ketinggian 3 atau 4 meter sekitar 6 orang untuk menyelamatkan orang lain tidak terlalu parah sering terjadi petugas alami seperti terinjak benda tajam, paku atau kayu-kayu yang runcing dan pecahan kaca dikarenakan tidak lengkap menggunakan alat pelingdung diri, masih kurangnya pintu darurat, PPPK, dan ambulance dan kurangnya memberikan pelayanan kesehatan dengan baik dan maksimal". Hasil wawancara di atas masih juga terdapatnya persoalan kurangnya komunikasi kemdian adanya persoalan kurangnya memberikan pelayanan kesehatan dengan maksimal,dan terjadinya kecelakaan kerja. Dan terdapatnya sebagian petugas yang tidak mempedulikan keselamatan kesehatan kerjanya walaupun aturan Standar Operasional Prosedur (SOP) keselamatan kesehatan kerja telah diterapkan. Keselamatan kesehatan kerja penting karena kesehatan yang buruk dan kerugian bagi pekerja dan keluarganya.
Hal penting yang perlu diperhatikan para petugas Dinas Pemadam Kebakaran Kota Padang yaitu ketelitian yang tinggi. Ketelitian yang dimaksud disini yaitu tidak mempunyai sikap lalai dapat berakibatkan fatal bagi para petugas Dinas Pemadam Kebakaran Kota Padang. Lalai dalam hal ini seperti tidak memakai helm pelindung yang dapat merusak kepala, tidak memakai kacamata pelindung,sepatu pelindung dan alat pelindung lainnya.

Budaya kerja berkaitan dengan keselamatan kesehatan kerja dimana didalam budaya kerja adanya ketelitian dan komunikasi. Didalam keselamatan kesehatan kerja ketelitian sangat diperlukan dimana ketellitian dalam penempatan benda-benda yang berbahaya agar tidak terjadinya kecelakaan kerja sedangkan komunikasi, sangat berkaitan dengan keselamatan kesehatan kerja dimana didalam keselamatan kesehatan kerja adanya penyediaan program sosialisasi terhadap pegawai agar tidak terjadinya kecelakaan kerja bagaimana bisa penyediaan promgram sosialisasi ini berjalan dengan efektif apabila masih adanya kurangnya komunikasi antara sesama petugas.

Dari uraian yang penulis jelaskan diatas maka penulis mempunyai ketertarikan meneliti dengan topik "Pengaruh Budaya Kerja Terhadap Keselamatan Kesehatan Kerja Dinas Pemadam Kebakaran Kota Padang".

Tujuan penelitian ini adalah untuk mengetahui pengaruh budaya kerja terhadap keselamatan kesehatan kerja dinas pemadam kebakaran kota padang.

\section{TINJAUAN PUSTAKA}

Rastology dalam Aldri Frinaldi (2014: 182) budaya kerja ialah nilai-nilai yang dapat menuntut mereka untuk bekerjaan yang berkualitas dan produktif. Triguno dalam Aldri (2011:53) memberikan gambaran tentang budaya kerja sebagai filosifi yang didasarkan pada pandangan hidup sebagai nilai yang menjadi ciri, kebiasaan dan kekuatan pendorong 
membudaya dalam kehidupan suatu kelompok masyarakat atau organisasi, dari sikap menjadi perilaku, kepercayaan, citacita, pendapat dan tindakan yang terwujud sebagai kerja maupun bekerja.

Budaya kerja yang baik menurut Puspita (dalam Aldri Afrinaldi, 2014: 182) manfaatnya antara lain (a) menjaga lingkungan kerja seimbang, (b) menciptakan lingkungan kerja teratur, (c) menciptakan lingkungan kerja yang memakmurkan dan mensejahterahkan pekerjaan, (f) mempromosikan etos kerja.

\section{Keselamatan Kesehatan Kerja}

Reliafiana (2012) keselamatan kerja K3 merupakan pemikiran dan harapan dapat mencegah terjadinya berbagai bentuk kecelakaan, kecelakaan kerja merupakan kejadian tidak terduga dapat menganggu proses kerja yang telah direncanakan, namun korban terluka dan tewas dalam arti kecelakaan kerja tidak selalu terjadi.

Menurut ilmu pengetahuan keselamatan kesehatan kerja sebagai konsep ilmiah hal ini dapat diartikan sebagai konsep ilmiah dan penerapannya untuk mencegah kebakaran, kecelakaan, ventilasi, populasi. Undang-undang yang mengatur tentang Keselamatan Kerja adalah Undang-Undang Republik Indonesia Nomor 1 Tahun 1970 diubah dengan Undang-Undang No. 13 Tahun 2003 Pasal 86 ayat 1 menyatakan bahwa semua pekerja/karyawan berhak untuk merlindungi keselamatan kesehatan kerja di tempat kerja mengacu pada perlindungan kesejaheraan fisik membantu untuk mencega terjadinya kecelakaan atau kecelakaan kerja (Malthis dan Jackson, 2002)

Anwar Prabu Mangkunegara (2011:162) upaya peningkatan keselamatan kesehatan kerja dengan cara berikut: a) pencegahan dan mengurangi kebakaran dan kecelakaan ledakan, b) memberikan alat pelindung diri kepada karyawan yang bekerja di lingkungan yang menggunakan peralatan berbahaya, c) mengukur suhu, kelembaban, kebersihan udara, penggunaan warnah ruangan kerja, pencahayaan yang cukup terang, penguuran mitigasi dan pencegahan kebisingan, d) Pemberian dan pengobatan penyakit, e) menjaga kebersihan dan ketertiban, serta keharmonisan dalam lingkungan kerja, f) menciptakan tempat kerja yang memotivasi karyawan.

Moenir dalam Rahman (2009: 13) indikator keselamatan kesehatan kerja: 1. Letakkan barang agar tidak melukai di dalam atau di sekitar tempat kerja, 2. Melindungi pekerja yang menyediakan peralatan kerja dapat ,menyebabkan kecelakaan dengan menyediakan alat pelindung yang memadai dan unggul, 3.Menyediakan peralatan yang dapat digunakan sebagai alat pencegahaa, bantuan dan perlindungan, 4. Memberikan program sosialisasi pencegahan kecelakaan yang diberikan perusahaan kepada karyawan dan pekerja, 5. Lingkungan medis dapat dilihat dari sikap perusahaan terhadap lingkungan kerja. a) Lingkungan kerja yang sukses, b) Suhu dan ventilasi limbah tempat kerja dan system pengolahan limba industri, 6. Lingkungan kesehatan pekerja, upaya perusahaan dalam meningkatkan kesehatan karyawan, terlihat pada penyediaan fasilitas air bersih dan kamar mandih., 7. Mencegah kesehatan pekerja yaitu pelayanan kesehatan pekerja.

Mangkunegara (2002:158), tujuan keselamatan kesehatan kerja adalah: 1) Menjamin bahwa semua karyawan mendapatkan jaminan kesehatan dan keselamatan fisik, sosiologi dan psikologis, 2) Menjamin bahwa semua perlengkapan dan perelengakapan digunakan secara maksimal 3) menjaga semua produk tetap terjaga, 4) Memastikan status gizi dan perbaikan, 5) Meningkatkan kenikmatan kerja, keharmonisan kerja, dan partipasi dalam bekerja 6) Kesehatan akibat lingkungandan keadaan ditempat kerja, 7) Semua karyawan terlindungi dan nyaman di tempat kerja untuk menghindari masalah.

\section{Keselamatan Kerja}

Keselamatan kerja Leon C.Megginson dalam Riska (2019:19) mencakup kedua istilah resiko keselamatan dan kesehatan. 
Keselamatan kerja mengacu pada kondisi aman atau terjamin karena rasa sakit, kerusakan atau kehilangan ditempat kerja. Risiko ialah aspek lingkungan kerja menyebabkan ketakutan, kehilangan daya, mati rasa, lebab dan patah tulang.

Menurut Marwansyah (2012:358) faktor kontribusi terhadap kecelakaan kerja ialah: 1) Peralatan tidak memadai/salah rancangannya dapat menimbulkan kejadian yang tidak diharapkan akan menimbulkan kecelakaan, 2) Kondisi kerja dapat mempengaruhi pekerja secara tidak langsung, dan oleh karena itu dapat juga menyebabkan terjadinya kecelakaan. Faktor-faktor itu antara lain:a. Kesemrawutan tempat kerja, b. Kebisingan, c. Temperatur, dan Ventilasi, e. Pencahayaan 3) Manusia yaitu kinerja para karyawan dapat meningkatkan risiko terjadinya kecelakaan.

Berdasarkan Undang-undang nomor 1 juga tahun 1970 persyaratan keamanan : 1) Pencegahan kecelakaan, 2) Pengurangan kebakaran 3) Pengurangan risiko ledakan, 4) Memberi kesempatan menyelamatkan diri pada waktu kebakaraan atau kejadiankejadian lain yang berbahaya, 5) Memberi bantuan pada kecelakaan, 6) Memberi alat pelindung diri pada para pekerja, 7) Memperoleh penerangan yang cukup dan sesuai, 8) Menyelenggarakan suhu dan lembab udara yang baik, 9) Memelihara kebersihan, keseharan dan ketertiban, 10) Menyelenggarakan penyegaran udara yang cukup, 11) Mencegah timbulnya penyakit akibat kerja baik, keracunan infeksi dan penularan.

\section{Kesehatan Kerja}

UU Nomor 23 tahun 1992 menyebutkan bahwa kesehatan kerja diterapakan untuk mencapai produktivitas kerja terbaik. Dilam kesehatan kerja mencakup layanan , pencegahan penyakit akibat kerja, dan syarat kesehatan kerja.

Mondy dan Noe (2005 :360). "Kesehatan kerja adalah pelepasan dari kekerasan fisik. Resiko kesehatan adalah faktor lingkungan kerja yang bekerja melebihi jangka waktu tertentu, lingkungan yang dapate menyebabkan stres emosional atau gangguan fisik.

Lalu Husni (2001:106-107) tujuan kesehatan yaitu: a. Menjaga kesehatan jasmani, psikologis b. Melindungi pekerjaan dari masalah kesehatan memicu kondisi kerja, c. Mengembangkan kegiatan.

\section{METODE PENELITIAN}

Berdasarkan judul dan masalah yang dipertimbangan jenis penelitian ini kuantitatif asosiatif. Penelitian ini dilaksanakan Dinas Pemadam Kebakaran Kota Padang Jl. Rasuna Said No. 56, Jati baru, Kecamatan Padang Timur., Kota Padang, Sumatera Barat. Operasional variabelnya ada 2 budaya kerja (X), keselamatan kesehatan kerja (Y). Populasi penelitian ini sebanyak 172 orang karyawan Damkar Kota Padang. Sampel dipilih secara acak menggunakan teknik purposive sampling. Sampel diambil dengan menggunakan rumus Slovin 5\% dan terdiri dari 120 sampel. Pengumpulan data dengan cara penyebaran angket yang menggunakan skala likert, analisis data deskriptif. 
HASIL DAN PEMBAHASAN

Tabel 1. Hasil Koefisien Determinasi Variabel X Terhadap Y

Model Summary ${ }^{b}$

\begin{tabular}{|l|c|r|r|r|r|}
\hline Model & R & R Square & $\begin{array}{c}\text { Adjusted R } \\
\text { Square }\end{array}$ & $\begin{array}{c}\text { Std. Error of the } \\
\text { Estimate }\end{array}$ & Durbin-Watson \\
\hline 1 & $.609^{\mathrm{a}}$ & .371 & .366 & .39237 & 1.579 \\
\hline
\end{tabular}

a. Predictors: (Constant), Budaya_kerja

b. Dependent Variable: keselamatan_kesehatan

Dari hasil output diatas di atas, menjelaskan bahwa $R$ Square dalam penelitian ini sebesar 0.371 . Hal ini berarti pengaruh sub variable budaya kerja terhadap keselamatan kesehatan kerja
Dinas Pemadam Kebakaran Kota Padang sebesar $37.1 \%$ sedangkan sisanya $62,9 \%$ berpengaruh dari penelitian lain yang tidak terdapat dalam penelitian ini.

Tabel 2. Hasil Uji T Variabel Budaya Kerja terhadap Keselamatan kesehatan kerja Coefficients $^{\mathrm{a}}$

\begin{tabular}{|c|c|c|c|c|c|c|c|}
\hline \multirow[b]{2}{*}{ Model } & \multicolumn{2}{|c|}{$\begin{array}{l}\text { Unstandardized } \\
\text { Coefficients }\end{array}$} & \multirow{2}{*}{$\begin{array}{c}\begin{array}{c}\text { Standardized } \\
\text { Coefficients }\end{array} \\
\text { Beta }\end{array}$} & \multirow[b]{2}{*}{$\mathrm{T}$} & \multirow[b]{2}{*}{ Sig. } & \multicolumn{2}{|c|}{$\begin{array}{c}\text { Collinearity } \\
\text { Statistics }\end{array}$} \\
\hline & B & Std. Error & & & & Tolerance & VIF \\
\hline 1 (Constant) & 1.137 & .248 & & 4.594 & .000 & & \\
\hline Budaya_kerja & .653 & .078 & .609 & 8.350 & .000 & 1.000 & 1.000 \\
\hline
\end{tabular}

a. Dependent Variable: kesehatan_keselamatan

Dari data hasil output diatas, dapat diketahui bahwa nilai signifikansi dari variable budaya kerja dan keselamatan kesehatan kerja adalah 0,000 lebih kecil dari 0,05 .. Didapatkan persamaan regresi antara budaya kerja (X) terhadap keselamatan kesehatan kerja (Y) adalah $\mathrm{Y}=1,137+0,653 \quad \mathrm{X}$ dan dari hasil perhitungan tersebut didapatkan nilai $\mathrm{t}$ (hitung) 8,350 yang menunjukkan bahwa hipotesis yang diajukan diterima dan budaya kerja berpengaruh terhadap keselamatan kesehatan kerja.

Hasil perhitungan pada tabel coefficients di atas, didapatkan persamaan regresi antara budaya kerja (X) terhadap keselamatan kesehatan kerja (Y) juga menunjukkan signifikansi konstanta. Dari hasil uji t tersebut hasil uji $\mathrm{t}$ tersebut dijelaskan bahwa:

1) Nilai konstanta sebesar 1,1137 maksudnya jika keselamatan kesehatan kerja dikatakan nol (0) maka budaya kerja sebesar 1,1137.

2) Koefisien budaya kerja 0,653 artinya setiap peningktan budaya kerja sebesar 1 satuan dan akan meningkatkan budaya kerja sebesar 0,653 dan sebaliknya dengan kemungkinan variabel lainnya.

3) Dari hasil perhitungan tersebut juga didapatkan nila Sig.0,00 $<0,05$ dengan demikian berarti dapat disimpulkan 
bahwa variable $\mathrm{X}$ (budaya kerja) berpengaruh terhadap variable $\mathrm{Y}$ (keselamatan kesehatan kerja).

\section{PENUTUP}

Berdasatrkan hasil penelitian diatas dapat disimpulkan ternyata budaya kerja dapat mempengaruhi keselamatan kesehatan kerja maka penelitian ini dapat mmeperkut teroi budaya kerja dan keselamatan kerja dinas pemadam kebakaran kota padang.

Dinas pemadam kebakaran kota Padang maka lebih meningkatkan lagi budaya kerja dengan sebaik-baiknya agar memberikan kontribusi untuk keselamatan kesehatan kerja dan pada akhirnya keselamatan kesehatan kerja menjadi meningkat. Dapat dipahami dari penelitian ini masih kurang optimal, maka diharapkan untuk penelitian selanjutnya agar lebih melengkapi penelitian dengan melakukan studi yang lebih detail yang melibatkan variable lain.

\section{DAFTAR KEPUSTAKAAN}

Aldri Frinald dan Muhammad Ali Embi.2011. Pengaruh Budaya Kerja Etnik.

Aldri Frinaldi 2014. Pengaruh Budaya Kerja Pegawai Negeri Sipil Terhadap Pelayanan Publik di Dinas Terhadap Pelayanan Publik di Dinas Catatan Sipil dan Kependudukan Kota Payakumbuh Fakultas Ilmu Sosial Universitas Negeri Padang. Vol XXI No. 2 Tahun 2014.

Anwar Prabu Mangkunegara. 2011. Manajemen Sumber Daya Manusia Perushaan. Bandung: PT Remaja Rosdakarya Offset.

Erliana (2017). Pengaruh Kepemimpinan Dan Budaya Orgaisasi Terhadap Penerapan Budaya Keselamatan Kerja ( Di Perusahaan Konstruksi PT Sinai Indonesai ). Jurnal Teknik Sipil-UCY, Vol XII No.1, Februari 2017. ISSN: 1907-2368.
Manullang. 2006. Manajemen Personalia. Yogyakarta: Gadjah Mada University Perss.

Mangkunegara, Anwar Prabu, AA. (2001). Manajemen Sumber Daya Manusia Perusahaan. Bandung: Remaja Rosdakarya.

Robert, Mathis\& John Jakson. 2002. Manajemen Sumber Daya Manusia. Jakarta: Salemba Empat.

Relieifiana, Y. 2012. Perlindungan Hukum Keselamatan Dan Kesehatan Kerja (K3) Buruh/Pekerja Pemadam Kebakaran (DAMKAR) Pt. Krakatau Steel (Persero) Tbk Menurut UndangUndang Nomor 13 Tahun 2003 Tentang Ketenagakerjaan Juncto Undang-Undang Nomor 1 Tahun 1970 Tentang Keselamatan Kerja. Tugas Akhir. Fakultas Hukum Universitas Sultan Agung Tirtayasa. Banten. (tidak dipulsikasikan).

Undang-Undang Nomor 1 Tahun 1970 tentang Keselamatan Kerja.

Undang-Undang Nomor 13 tahun 2003 tentang Ketenagakerjaan. 